\title{
Covid-19 Infection
}

\author{
Serkan Atici* \\ Division of Pediatric Infectious Diseases, Marmara University School of Medicine, Turkey
}

Journal of Clinical Infectious Diseases: Open Access (ISSN: 26844559) is a peer reviewed journal.

JID aims to publish the most reliable and complete information on discoveries and current developments in the form of research articles, review articles, case reports and short communication.

This journal welcomes submissions via online submission system or email to the Editorial Office at submissions@hilarispublisher.com

The journal is developing continuously. It is our pleasure to declare that during year 2020, special issue on Symptoms and signs of coronavirus infection.

Infection control prevents or stops the spread of infections in healthcare settings.

An overview of how contaminations spread, approaches to forestall the spread of diseases, and more definite proposals by sort of medical services setting:

\section{How Infections Spread}

Germs are a piece of regular daily existence and are found in our air, soil, water, and in and on our bodies. A few germs are useful, others are hurtful. Numerous germs live in and on our bodies without making mischief and some even assist us with remaining sound. Just a little part of germs are known to cause contamination.

\section{How Do Infections Occur?}

A contamination happens when germs enter the body, increment in number, and cause a response of the body.

Three things are important for a disease to happen:

- $\quad$ Source: Places where irresistible infectious agents (germs) live (e.g., sinks, surfaces, human skin)

- $\quad$ Susceptible: Person with a way for germs to enter the body

- Transmission: a way germs are moved to the vulnerable person

\section{Source}

A Source is an irresistible agent or germ and alludes to an infection or a microorganism

In medical services settings, germs are found in numerous spots. Individuals are one wellspring of germs including:

- Patients

*Address for Correspondence: Serkan Atici, Division of Pediatric Infectious Diseases, Marmara University School of Medicine,Turkey, E-mail: aticiserkan@ yahoo.com

Copyright: (c) 2020 Serkan Atici. This is an open-access article distributed under the terms of the Creative Commons Attribution License, which permits unrestricted use, distribution, and reproduction in any medium, provided the original author and source are credited.

Received 10 September 2020; Accepted 19 September 2020; Published 26 September 2020
- Healthcare workers

- Visitors and family members

i. Individuals can be debilitated with manifestations of a disease or colonized with germs (not have side effects of a contamination yet ready to pass the germs to other people).

ii. Germs are likewise found in the medical care condition. Instances of ecological wellsprings of germs include:

iii. Dry surfaces in understanding consideration territories (e.g., bed rails, clinical gear, ledges, and tables)

iv. Wet surfaces, damp conditions, and biofilms (e.g., cooling pinnacles, fixtures and sinks, and gear, for example, ventilators)

v. Indwelling clinical gadgets (e.g., catheters and IV lines)

vi. Dust or rotting garbage (e.g., development residue or wet materials from water spills)

\section{Susceptible Person}

A susceptible person is somebody who isn't immunized or in any case, or a person with a weakened immune system who has a path for the germs to enter the body. For a contamination to happen, germs must enter a defenseless individual's body and attack tissues, increase, and cause a response.

Devices like IV catheters and careful cuts can give a gateway, though a solid safe framework helps battle contamination.

At the point when patients are debilitated and get clinical treatment in medical care facilities, the accompanying components can build their powerlessness to contamination.

i. Patients in medical care who have fundamental ailments, for example, diabetes, malignancy, and organ transplantation are at expanded danger for disease in light of the fact that frequently these sicknesses decline the invulnerable framework's capacity to battle contamination.

ii. Certain meds used to treat ailments, for example, anti-infection agents, steroids, and certain malignancy battling meds increment the danger of certain kinds of contaminations.

iii. Lifesaving clinical medicines and systems utilized in medical services, for example, urinary catheters, cylinders, and medical procedure increment the danger of disease by giving extra ways that germs can enter the body.

\section{Transmission}

Transmission refers to the way germs are moved to the helpless individual.

Germs don't move themselves. Germs rely upon individuals, nature, and additionally clinical gear to move in medical care settings.

There are a couple of general ways that germs travel in medical services settings - through contact (i.e., touching), showers and sprinkles, inward breath, and sharps wounds (i.e., when somebody is incidentally stayed with a pre-owned needle or sharp instrument).

i. Contact moves germs by contact (model: MRSA or VRE). For 
instance, medical services supplier hands become tainted by contacting germs present on clinical gear or high touch surfaces and afterward convey the germs on all fours to a defenseless individual when appropriate hand cleanliness isn't performed before contacting the susceptible person.

ii. Sprays and sprinkles happen when a contaminated individual hacks or sniffles, making beads which convey germs short separations (inside around 6 feet). These germs can arrive on a helpless individual's eyes, nose, or mouth and can cause disease (example: pertussis or meningitis).

iii. Close go inward breath happens when a bead containing germs is sufficiently little to take in yet not solid over separation.

iv. Inhalation happens when germs are aerosolized in little particles that make due on air flows over huge spans and time and contact a vulnerable individual. Airborne transmission can happen when contaminated patients hack, talk, or sniffle germs into the air (model: TB or measles), or when germs are aerosolized by clinical hardware or by dust from a development zone (model: Nontuberculous mycobacteria or aspergillus). v. Sharps wounds can prompt contaminations (model: HIV, HBV, $\mathrm{HCV}$ ) when blood borne microbes enter an individual through a skin cut by a pre-owned needle or sharp instrument.

\section{Infection Prevention and Control}

- Hand Hygiene

- Environmental cleanliness

- Screening patients

- Inoculations

- Observation

- $\quad$ Anti-toxin stewardship, etc.

How to cite this article: Serkan Atici. "Covid-19 Infection". Clin Infect Dis 4 (2020) doi: 10.37421/jid.2020.4.129 